\title{
Microarray analysis of hepatic genes differentially expressed in the presence of the unsaponifiable fraction of olive oil in apolipoprotein E-deficient mice
}

\author{
Sergio Acín ${ }^{1}$, María A. Navarro ${ }^{1}$, Javier S. Perona ${ }^{2}$, Joaquín C. Surra ${ }^{1}$, Natalia Guillen ${ }^{1}$, Carmen Arnal $^{3}$, \\ Alfonso J. Sarría ${ }^{1}$, José M. Arbonés-Mainar ${ }^{1}$, Ricardo Carnicer ${ }^{1}$, Valentina Ruiz-Gutiérrez ${ }^{2}$ and \\ Jesús Osada ${ }^{1} *$ \\ ${ }^{1}$ Departamento de Bioquímica y Biología Molecular y Celular, Facultad de Veterinaria, Instituto Aragonés de Ciencias de la Salud \\ (Universidad de Zaragoza-Dirección Salud del Gobiemo de Aragón), Miguel Servet 177, E-50013 Zaragoza, Spain \\ ${ }^{2}$ Group of Nutrition and Lipid Metabolism, Instituto de la Grasa, Avda Padre Tejero 4,E-41012, Sevilla, Spain \\ ${ }^{3}$ Departamento de Patología Animal, Facultad de Veterinaria, Universidad de Zaragoza, Miguel Servet 177, E-50013, Zaragoza, Spain
}

(Received 30 May 2006 - Revised 18 September 2006 - Accepted 10 October 2006)

\begin{abstract}
The hypothesis that the unsaponifiable fraction of olive oil dramatically influences hepatic gene expression was tested in mice. Two olive oils, obtained from the same olive cultivar but by different technological procedures, were characterized to show that they differed mainly in terms of the composition/quantity of this unsaponifiable fraction. Using DNA microarrays, hepatic gene expression was analysed in apoE-deficient mice fed one of two isoenergetic, isonitrogenous diets containing either $10 \%(\mathrm{w} / \mathrm{w})$ olive oil or unsaponifiable fraction-enriched olive oil. To provide an initial screening of potential candidate genes involved in a differential response, only genes with remarkably modified expression (signal $\log _{2}$ ratio $>3$ or $<-3$ ) were further considered. The eleven genes fulfilling these prerequisites were confirmed by quantitative RT-PCR, and then analysed in apoE-deficient mice with a C57BL/6J genetic background. Orosomucoid and serum amyloid A2 were upregulated (to variable extents depending on the genetic background) in the absence of hepatic steatosis and inflammation. Fabp5 and Mt 2 were also strongly upregulated. Several proteases were highly suppressed by the unsaponifiable-enriched olive diet, independent of the genetic background. The findings indicate that change in the expression of these genes is a good marker of the intake of the unsaponifiable fraction of olive oil. The results highlight the important biological effects of the unsaponifiable fraction of olive oil. The term 'monounsaturated fatty acid-enriched oil' no longer appears appropriate for describing all the oils to which it is currently applied since it does not adequately reflect that they have different biological effects.
\end{abstract}

Apolipoprotein E-deficient mice: Olive oil: Unsaponifiable fraction

The 'Seven Countries' study showed that the so-called Mediterranean diet is associated with a reduced risk of cardiovascular mortality despite its associated high intake of fat, mainly derived from olive oil (Keys et al. 1986; Keys, 1995). It has also been shown that MUFA-containing oils reduce total and LDL cholesterol levels with no proportionate reduction of HDL cholesterol levels (Mattson \& Grundy, 1985; Mensink \& Katan, 1989; Mata et al. 1992). A whole panoply of experimental work has been designed to explain these epidemiological and clinical data. However, MUFA-enriched diets have selective physiological effects in man, indicating that other components, e.g. TAG species or non-fatty acids, rather than the oleic acid content alone, might be responsible for the benefits of virgin olive oil (Ruiz-Gutierrez et al. 1996; KrisEtherton et al. 1999; Abia et al. 2001; Perona et al. 2003, 2006). Similar findings have also been described in animal studies dealing with the effects of olive oil on the vascular wall (Calleja et al. 1999; Herrera et al. 2001). When studying the biological effects of olive oil it should be remembered that it is more than a simple mixture of fatty acids, and that it contains other biologically active substances such as tocopherols, polyphenols and phytosterols, some of which have antioxidant and anti-inflammatory activities (Visioli et al. 2000, 2003; de la Puerta et al. 2001; de la Puerta-Vazquez et al. 2004; Perona et al. 2006).

In Spain, unsaponifiable fraction-enriched olive oil is known as orujo or olive-pomace oil, and is extracted by the secondary centrifugation of the residue left after obtaining virgin olive oil. Improved procedures for the extraction of this oil now allow it to be obtained with higher concentrations of terpenoids, tocopherols, phytosterols and waxes from the epicarp of the olive - compounds that are in low concentration in virgin olive oil (Pérez-Camino \& Cert, 1999). The nutritional value of this innovative olive oil preparation has not yet been studied, although the biological activity of most of these compounds is now being unveiled. We recently reported the vasorelaxant effects of oleanolic acid and erythrodiol, two triterpenoids found in orujo, on rat aorta

\footnotetext{
Abbreviations: OO diet, diet supplemented with olive oil; qRT-PCR, quantitative real-time RT-PCR; UEOO diet, diet supplemented with unsaponifiable fractionenriched olive oil.

*Corresponding author: Dr Jesús Osada, fax +34 976761 612, email Josada@unizar.es
} 
(Rodriguez-Rodriguez et al. 2004), as well as the improvement obtained with the unsaponifiable fraction of virgin olive oil in the balance between the vasoprotective and prothrombotic factors released by endothelial cells (Sanchez Perona et al. 2004).

The liver produces a number of lipoproteins (VLDL and HDL), apo and enzymes. The latter (hepatic lipase, lecithin cholesterol acyltransferase and phospholipid transfer protein) are involved in the plasma transformation of lipoproteins (den Boer et al. 2004). ApoE-deficient mice develop spontaneous atherosclerosis (Osada et al. 2000) and cognitive deficits resembling those of Alzheimer's disease and ageing, and therefore provide a model for all these problems (Masliah et al. 1995; Oitzl et al. 1997; Krzywkowski et al. 1999). When fed high-fat diets these mice show slight hepatic steatosis that responds to dietary manipulations such as changing the type of linoleic acid isomer provided (Arbonés-Mainar et al. $2006 a$ ). These steatotic variations have been associated with the development of atherosclerotic lesions (Arbonés-Mainar et al. 2006b). Thus, the liver may undergo important metabolic changes under the influence of olive oil, mediated through changes in plasma lipoprotein concentration, and the steatotic-prone liver of apoE-deficient mice offers an excellent model in which to verify this. To test the hypothesis that the unsaponifiable fraction of olive oil significantly influences hepatic gene expression, apoE-deficient mice of different genetic backgrounds were fed diets supplemented with either $10 \%(\mathrm{w} / \mathrm{w})$ olive oil or $10 \%$ unsaponifiable fraction-enriched olive oil. Gene expression was then determined by microarray analysis and confirmed by real-time RT-PCR.

\section{Methods and material}

\section{Animals}

The experimental animals were seventeen two-month-old male, homozygous apoE KO mice with a C57BL6J × OLA129 genetic background, and twelve homozygous apoE $\mathrm{KO}$ mice with a C57BL6J genetic background, all bred at the Unidad Mixta de Investigación, University of Zaragoza. To confirm that the initial plasma cholesterol and TAG concentrations of these animals were the same, blood samples were taken (after overnight fasting) from the retroorbital plexus after isofluorane anaesthetization. All mice were housed in sterile filter-top cages in rooms maintained under a $12 \mathrm{~h}$ light$12 \mathrm{~h}$ dark cycle. All had access ad libitum to food and water. The study protocol was approved by the Ethics Committee for Animal Research of the University of Zaragoza. Body weights and food intake were recorded throughout the experiment.

\section{Diets}

Two study groups were established: (1) one received a chow diet (Teklad Mouse/Rat Diet no. 2014; Harlan Teklad, Harlan Ibérica, Barcelona, Spain) supplemented with $10 \%$ (w/w) olive oil obtained by a conventional procedure (OO diet) ( $n 9$ and $n 6$ for the first and second experiments respectively; see later), and (2) the other received the same chow diet but supplemented with $10 \%(\mathrm{w} / \mathrm{w})$ unsaponifiable fraction-enriched olive oil (UEOO diet; $n 8$ and $n 6$ for the first and second experiments respectively; see later). This unsaponifiable fraction-enriched olive oil was manufactured by an innovative procedure (Pérez-Camino \& Cert, 1999). Both olive oils were obtained from the same cultivar, contained the same TAG species and both were refined to eliminate the influence of soluble phenol compounds. All diets were prepared weekly and stored in an $\mathrm{N}_{2}$ atmosphere at $-20^{\circ} \mathrm{C}$. Fresh food was provided daily. The animals were fed the experimental diets for 11 weeks; both were well tolerated. The unsaponifiable fraction was characterized as previously described (de la Puerta-Vazquez et al. 2004).

\section{Plasma analyses}

At the end of the experimental period and after an overnight fast, the animals were killed by suffocation with $\mathrm{CO}_{2}$ and blood was drawn from their hearts. Plasma serum amyloid A concentrations were evaluated by immunoassay using a rat monoclonal anti-mouse serum amyloid A antibody (BioSource International, Camarillo, CA, USA) as the primary antibody (intra-day $\mathrm{CV}$ of this assay was $15 \%$ for positive control). Plasma $\alpha 1$-acid glycoprotein (orosomucoid) concentrations were determined by the single radial immunodiffusion test using the mouse $\alpha 1-\mathrm{AG}$ plate kit (Cardiotech Services, Louisville, KY, USA) and were processed the same day (intra-day $\mathrm{CV}$ of this assay was $4 \%$ for positive control).

\section{Analysis of hepatic lipids}

To determine hepatic cholesterol and TAG concentrations, lipids were extracted from $100 \mathrm{mg}$ tissue using the method of Folch et al. (1957), employing 2,6-di-tert-butyl-p-cresol as an antioxidant. The extracted lipids were redissolved in $1 \mathrm{ml}$ of chloroform-methanol $(2: 1, \mathrm{v} / \mathrm{v})$ and stored at $-20^{\circ} \mathrm{C}$ until analysis. The lipid classes were determined by HPLC as described by Perona \& Ruiz-Gutierrez (2004). Standard solutions of cholesteryl oleate, triolein, cholesterol and phosphatidylcholine, prepared in chloroform-methanol $(2: 1$, $\mathrm{v} / \mathrm{v})$, were used for the identification and quantification of cholesteryl esters, TAG, free cholesterol and phospholipids, respectively.

\section{RNA isolation, Affymetrix oligonucleotide array hybridization} and data analysis

Immediately after the animals were killed the livers were removed and frozen in liquid nitrogen. RNA from each liver was isolated using Trigent reagent (MRC, Cincinatti, $\mathrm{OH}$, USA). DNA contaminants were removed by TURBO DNAse treatment using the DNA removal kit from AMBION (Austin, TX, USA). RNA was quantified by absorbance at $A_{260 / 280}$ (the $A_{260 / 280}$ ratio was greater than 1.75). The integrity of the $28 \mathrm{~S}$ and $18 \mathrm{~S}$ ribosomal RNA was verified by agarose formaldehyde gel electrophoresis followed by ethidium bromide staining. Images were captured and analysed using a Bio-Rad image analysis system and Molecular Analyst (Bio-Rad, Madrid, Spain). The 28S/18S ratio was greater than 2 .

Aliquots $(20 \mu \mathrm{g})$ of total liver RNA from each mouse of each group ( $n 9$ for the OO group and $n 8$ for the UEOO group) were pooled to avoid problems of individual variation, 
and purified using the RNeasy system (Quiagen, Barcelona, Spain). Total liver RNA ( $8 \mu \mathrm{g})$ was then used for biotin labelling. Hybridization, washing, scanning and analysis with the Affymetrix GeneChip Murine Genome MOE430A array (Affymetrix, Santa Clara, CA, USA) were performed according to the standard Affymetrix protocols used at Progenika Biopharma (Derio, Spain). Fluorometric data were generated by Affymetrix software, and the fluorimetric signal adjusted so that all the probe sets provided intensities within a manageable range. Transcripts with signal intensities that were lower than the noise of the matrix $( \pm 3 \mathrm{SD})$ were not taken into account. The data obtained in the microarray hybridizations were processed with Microarray Suite 5.0 (Affymetrix) software. The identification of genes that were up- or down-regulated by the unsaponifiable fraction was performed by comparing gene expressions in the livers of animals from the two diet groups (significance set at $P<0.01$ ). Of these we selected only those whose signal $\log _{2}$ ratio was higher than 1.5 (up-regulated genes) or lower than -1.5 (down-regulated genes). Signal $\log _{2}$ ratio is now recommended by Affymetrix software and several authors (Gilsbach et al. 2006) because of the linear response observed in contrast to fold change. The complete datasets were deposited in the Gene Expression Omnibus (GEO) database (accession number GSE2261).

\section{Quantification of $m R N A$}

The differences in mRNA expression observed with the microarrays was confirmed by Northern blotting and quantitative real-time RT-PCR (qRT-PCR) analysis of individual samples. Northern blot analysis was performed as previously described (Acín et al. 2005). The mouse clones for apoa5 (4196296 IMAGE Clone) and ponl (4158951 IMAGE Clone) were obtained from MGC Geneservice (Cambridge, UK). The probes used were those previously described: apoa5 (Arbonés-Mainar et al. 2006a) and pon1 (Acín et al. 2005). A mouse $\beta$-actin fragment (Acín et al. 2005) was used to normalize the amount of RNA. Labelling and quantification were performed as previously described (Acín et al. 2005).

Equal amounts of DNA-free RNA from each sample of each animal were used in qRT-PCR analyses. First-strand cDNA synthesis and the PCR reactions were performed using the SuperScript III Platinum Two-Step qRT-PCR Kit with SYBR Green (Invitrogen, Madrid, Spain), according to the manufacturer's instructions and as previously described (Arbonés-Mainar et al. 2006a). The primers used were designed by Primer Express ${ }^{\circledR}$ (Applied Biosystems, Foster City, CA, USA): for chymotrypsinogen - sense, 5'-CAG CAC CAT GGC ATT CCT TT-3', antisense, 5'-GCA TCC TCT CCG TTG ACG AT-3'; for elastase 2 - sense, $5^{\prime}$-ACT GAA TTG CCG GGC ATC TA-3', antisense, 5'-GTT CCT TGC CAT CAC CGA GT-3'; for fatty acid binding protein 5 - sense, 5'-GAC GGT CTG CAC CTT CCA AG-3', antisense $5^{\prime}$-CAG GAT GAC GAG GAA GCC C-3'; for glucokinase - sense, 5'-ACG ACC CCT GCT TAT CCT CA-3', antisense, 5'-CAC GGT CCA TCT CCT TCT GC-3'; for leptin receptor - sense, 5'-TGA CTT GCA GAT GGT CAC CC-3', antisense, 5'-AAG CCG TCT CTC TGT AAG ACG C-3'; for metallothionein 2 - sense, 5'-TCG GAA TCT
TCA CTC TTC AAA CC-3', antisense, 5'-CCA TCG GAG GCA CAG GAG-3'; for nicotinamide N-methyltransferase sense, 5'-CCT GGG CAG TCT GCT CAA G-3, antisense, 5'-AAT GGT GTA ACC GGC CTC TTC-3; for orosomucoid

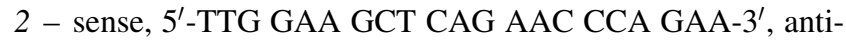
sense, 5'-TCG AAG CTC CAT CGT GTC ATT-3'; for pancreatic lipase 2 - sense, 5'-GGA GCC CAG CAC AGA TCA AC-3', antisense, 5'-GCC AGT TTT CTT CTC CCT TGT C-3'; for serum amyloid A 2 - sense, 5'-CTG GCT GGA AAG ATG GAG AC-3', antisense, 5'-TGT CCT CGT GTC CTC TGC-3'; for trypsin 4 - sense, 5'-CTT CAA TGC CTG GAT GCC C-3', antisense, 5'-CAG GAG ACA ATG CCC TGG AG-3'; and for $\beta$-actin - sense, $5^{\prime}$-CTG ACT GAC TAC CTC ATG AAG ATC CT-3', antisense, $5^{\prime}$ CTT AAT GTC ACG CAC GAT TTC C-3'. The specificity of the PCR reaction was confirmed by sequencing the products after their electrophoretic separation in agarose gels. Real-time RT-PCR reactions were performed in an ABI PRISM 7700 Sequence Detector (Applied Biosystems) following the standard procedure. The relative amount of all mRNA was calculated using the comparative $2^{-\Delta \Delta \mathrm{Ct}}$ method. $\beta$-actin mRNA was used as the invariant control.

\section{Liver histology analysis}

Aliquots of liver were stored in neutral formaldehyde and embedded in paraffin. Sections $(4 \mu \mathrm{m})$ were stained with haematoxylin and eosin and observed with a Nikon microscope.

\section{Statistical analysis}

The Mann-Whitney $U$ test, according to the Algoritm of Microarray Suite 5.0 (Affymetrix), was used to compare the mean fluorimetric signal intensities of eleven to twenty perfect match probe per probe set hybridized to liver RNA from the OO group with those obtained for the UEOO group and in either case subtracted the intensities of a similar number of mismatched probes (background hybridization). Significance was set at $P<0 \cdot 01$. Correlations between variables were tested by calculating the Spearman's rank-order correlation coefficient $\left(r_{\mathrm{s}}\right)$; tests were performed using Instat 3.02 software for Windows (GraphPad, San Diego, CA, USA).

\section{Results}

\section{Dietary characteristics}

Tables 1 and 2 show the lipid composition of the two olive oils used. Their composition in linolenic fatty acid, SFA and MUFA was similar (Table 1), but the composition of the unsaponifiable fraction was different (except for squalene) (Table 2): the unsaponifiable fraction-enriched olive oil had greater quantities of phytosterols, waxes, triterpenes (erythrodiol, uvaol and maslinic) and tocopherols.

No significant difference in weight gain (4.4 (SD 0.2) for the OO group compared to 4 (SD 0.3 ) $\mathrm{g}$ for the UEOO group) or food intake (3.9 (SD 0.3) for the OO group compared to 3.8 (SD 0.2) g for the UEOO group) was observed between the animals of the two diet groups. Similarly, the weight of 
Table 1. Fatty acid composition of the olive oils used $(\mathrm{g} / 100 \mathrm{~g}, \mathrm{w} / \mathrm{w})$

\begin{tabular}{lrc}
\hline Fatty acids & Olive oil & Unsaponifiable \\
\hline Myristic $(14: 0)$ & 0.02 & 0.02 \\
Palmitic $(16: 0)$ & 10.98 & 10.29 \\
Stearic $(18: 0)$ & 3.53 & 2.95 \\
Arachidic $(20: 0)$ & 0.42 & 0.45 \\
Behenic $(22: 0)$ & 0.12 & 0.17 \\
Lignoceric $(24: 0)$ & 0.05 & 0.07 \\
Palmitoleic $(16: 1)$ & 0.82 & 0.76 \\
Oleic $(18: 1)$ & 77.80 & 74.27 \\
Gadoleic $(20: 1)$ & 0.25 & 0.33 \\
Linoleic $(18: 2 n-6)$ & 4.52 & 8.07 \\
Linolenic $(18: 3 n-3)$ & 0.62 & 0.70 \\
SFA & 15.14 & 13.95 \\
MUFA & 78.87 & 75.36 \\
\hline
\end{tabular}

the liver appeared unaltered by the administration of either diet $(0.79$ (SD 0.05) and 0.76 (SD 0.02) g, respectively).

\section{Gene expression in livers of apoE-deficient mice fed the different diets}

To determine the changes in hepatic gene expression induced by the unsaponifiable fraction of olive oil, the expression of 22690 transcripts represented on the Affymetrix GeneChip Murine Genome MOE430A array was quantified in pooled liver samples of nine animals that received the $\mathrm{OO}$ diet and another eight that received the UEOO diet. The livers of OO animals expressed 10455 transcripts, while those of the UEOO animals expressed 10675 (identified as 'present' by Affymetrix software). Using the Mann-Whitney ranking feature of the Affymetrix software to determine significant differences in gene expression $(P<0.01)$, the increased expression of 920 sequences plus the reduced expression of 420 sequences was identified in samples from the animals on the UEOO diet compared to those on the OO diet when no multiple test correction was applied. When the latter was taken into consideration by removing expressions with similar gene symbols, identical accession number and identical UNIGENE number, the number of genes with increased and repressed expression was reduced to 660 and 324, respectively. To select the most relevant, only differentially regulated genes with a signal $\log _{2}$ ratio higher than 1.5 (for those genes up-regulated) or lower than -1.5 (for those repressed) were taken into account. Tables 3 and 4 list the genes whose mRNA reflected these expressions. Thirty genes fulfilled the criterion of showing increased expression as a response to the unsaponifiable fraction of olive oil (Table 3). Five of these genes coded for acute phase proteins (Orm1, Orm2, Orm3, Saa1 and Saa2), four coded for proteins belonging to the extracellular space (Apcs, Fgll, Prg4 and $S d c 4)$, three were involved in signal transduction $(E g f r$, Lepr and Sesn1), three in electron transport (Cyp17al, Cyp 2 b20 and Qscn6) and two in protein metabolism (Ren1 and Serpina3n). A further three were enzymes involved in acetyl-CoA $(P d k 4)$, fatty acid $(S c d 1)$ and bile acid ( $C y p 7 a 1)$ biosynthesis, two coded for ion binding proteins ( $M t 1$ and $M t 2)$, two for metabolite transport proteins (Fabp5 and Lcn2), four for proteins with miscellaneous functions (e.g. one was involved in apoptosis $(B c l 2 l)$, another was an enzyme involved in nicotinamide metabolism (Nnmt), one was a member of the complement cascade $(C f h)$ and one was a transcription factor (Gadd $45 g$ ). Finally, two genes coded for unknown expressed sequence tags. Twenty-four genes met the criterion of showing a reduced expression as a response to the presence of the unsaponifiable fraction of olive oil (Table 4). Of these, eight were involved in proteolysis (Cpa1, Cpb1, Chym, Ela1, Ela2, Ela3b, Prss2 and Try4), four in lipid metabolism (Clps, Cel, Pnlip and Pnliprp1), three in glutathione conjugation (Gsta2, Gsta4 and Gstm3), two coded for heat shock proteins (Hspala and Hspbl), two for transcription factors ( $N r l d l$ and $D b p$ ), one for an enzyme involved in carbohydrate metabolism $(G c k)$, three for proteins with miscellaneous functions (one extracellular receptor (Dmbt1), one enzyme involved in RNA metabolism (Rnase 1) and one cell surface protein $(S y c n)$ ), and finally one for an unknown expressed sequence tag.

To validate the results obtained with the microarray, the expressions of eleven genes - Chym, Ela2, Fabp5, Gck, Lepr, Mt2, Nnmt, Orm2, Pnlip, Saa2, Try4 - that were strikingly up- or down-regulated (signal $\log _{2}$ ratio $>3$ or $<-3$ ) were individually studied by specific qRT-PCR assays. $\beta$-actin was used to normalize the results that are shown in Table 5. The six up-regulated genes included in the validation analysis - Fabp5, Lepr, Mt2, Nnmt, Orm2, Saa2 - appeared

Table 2. Composition of the unsaponifiable fraction of the olive oils used $(\mathrm{mg} / \mathrm{kg}, \mathrm{w} / \mathrm{w})$

\begin{tabular}{lcc}
\hline Component & Olive oil & Unsaponifiable fraction-enriched olive oil \\
\hline Erythrodiol + uvaol & 17 & 500 \\
Maslinic acid & 0 & 110 \\
Squalene & 2600 & 2500 \\
Total phytosterols & 1120 & 2240 \\
Total tocopherols & 220 & 981 \\
Waxes & 120 & 3400 \\
\hline
\end{tabular}


Table 3. Hepatic genes up-regulated by the unsaponifiable fraction of olive oil ${ }^{\star}$

\begin{tabular}{|c|c|c|c|c|c|c|c|}
\hline Biological process & GenBank & Affymetrix ID & Name & Gene symbol & Olive oil & UE olive oil & Signal $\log _{2}$ ratio \\
\hline Acetyl-CoA biosynthesis & NM 013743 & 1417273 at & Pyruvate dehydrogenase kinase 4 & Pdk4 & 20.6 & $96 \cdot 1$ & 1.9 \\
\hline Acute phase response & BE628912 & 1451054_at & Orosomucoid 1 & Orm1 & 702 & 3087.5 & 2 \\
\hline Acute phase response & NM_011016 & 1420438_at & Orosomucoid 2 & Orm2 & 71.5 & $1496 \cdot 9$ & 3.9 \\
\hline Acute phase response & NM 013623 & 1450611 at & Orosomucoid 3 & Orm3 & $20 \cdot 7$ & $115 \cdot 1$ & $2 \cdot 3$ \\
\hline Acute phase response & NM_009117 & 1450788_at & Serum amyloid $\mathrm{A} 1$ & Saa1 & $2017 \cdot 4$ & $5175 \cdot 9$ & 1.5 \\
\hline Acute phase response & NM_011314 & 1449326_x_at & Serum amyloid A 2 & Saa2 & $858 \cdot 1$ & 4291.9 & $3 \cdot 3$ \\
\hline Apoptosis & NM 009743 & 1420887 a at & $\mathrm{Bcl}-\mathrm{xl}$ & $B c 121$ & 20.1 & 103 & 2.9 \\
\hline Bile acid metabolism & NM_007824 & 1422100_at & Cytochrome P450, 7a1 & Сур7а1 & $109 \cdot 9$ & 495.4 & 2.5 \\
\hline Metal binding protein & BC027262 & 1451612_at & Metallothionein 1 & Mt1 & $15 \cdot 1$ & 88.1 & 2.9 \\
\hline Metal binding protein & AA796766 & 1428942 at & Metallothionein 2 & Mt2 & $420 \cdot 7$ & 4657 & $3 \cdot 1$ \\
\hline Complement cascade & Al987976 & 1450876_at & Complement component factor $\mathrm{h}$ & Cfh & $70 \cdot 4$ & 234.3 & 1.8 \\
\hline Electron transport & NM_007809 & 1417017_at & Cytochrome P450, 17a1 & Cyp17a1 & 34.2 & $146 \cdot 1$ & 1.9 \\
\hline Electron transport & AF128849 & 1451787 at & Cytochrome P450, 2b20 & Сур2b20 & 185.3 & 615.6 & 1.8 \\
\hline Electron transport & AK004880 & 1420832_at & Quiescin Q6 & Qscn6 & $313 \cdot 2$ & 688.9 & 1.5 \\
\hline Extracellular space & NM_011318 & 1419059_at & Serum amyloid $\mathrm{P}$ & Apcs & $902 \cdot 2$ & $4829 \cdot 2$ & $2 \cdot 2$ \\
\hline Extracellular space & BC005679 & 1417654_at & Syndecan 4 & Sdc4 & 275.6 & 1978.7 & 2.9 \\
\hline Extracellular space & NM_021400 & 1449824_at & Proteoglycan 4 & Prg4 & $83 \cdot 8$ & $373 \cdot 2$ & $2 \cdot 1$ \\
\hline Extracellular space & BC021946 & 1424599_at & Fibrinogen-like protein 1 & Fgl1 & $1698 \cdot 1$ & 4164 & 1.6 \\
\hline Fatty acid synthesis & NM_009127 & 1415965 at & Stearoyl-coenzyme A desaturase & Scd1 & $195 \cdot 3$ & 721.1 & 1.8 \\
\hline Methyl transferase & AK006371 & 1432517_a_at & Nicotinamide $\mathrm{N}$-methyltransferase & Nnmt & $107 \cdot 1$ & $1158 \cdot 3$ & 3.4 \\
\hline Protease inhibitor & NM_009252 & 1419100_at & Proteinase inhibitor, A3N & Serpina3n & 935.4 & $2959 \cdot 6$ & 1.5 \\
\hline Proteolysis & NM_031192 & 1448975_s_at & Renin 1 & Ren1 & $48 \cdot 6$ & 269.9 & $2 \cdot 7$ \\
\hline Signal transduction & U42467 & 1425644_at & Leptin receptor & Lepr & $2 \cdot 8$ & $166 \cdot 1$ & $5 \cdot 8$ \\
\hline Signal transduction & U03425 & 1424932_at & Epidermal growth factor receptor & Egfr & $148 \cdot 6$ & $446 \cdot 8$ & 1.5 \\
\hline Signal transduction & BG076140 & 1433711_s_at & Sestrin 1 & Sesn 1 & 63.4 & 166.9 & 1.5 \\
\hline Transcription factor & AK007410 & 1453851_a_at & Growth arrest and DNA-damage-inducible 45 & Gadd $45 \mathrm{~g}$ & 96.5 & $240 \cdot 3$ & 1.5 \\
\hline Transport (fatty acids) & BC002008 & 1416022_at & Fatty acid binding protein 5 & Fabp5 & 32.6 & 238.5 & 3 \\
\hline \multirow[t]{3}{*}{ Transport (fatty acids) } & $\mathrm{X} 14607$ & 1427747_a_at & Lipocalin 2 & Lcn2 & $400 \cdot 9$ & $3304 \cdot 6$ & 2.9 \\
\hline & AK017926 & 1428306_at & Expressed sequence tag & - & 80.9 & 359.2 & 2.4 \\
\hline & AV291259 & 1429144 at & Expressed sequence tag & _- & 341.9 & $1280 \cdot 7$ & $1 \cdot 7$ \\
\hline
\end{tabular}

UE, unsaponifiable fraction-enriched.

* Data represent intensity of signal for each condition with the Affymetrix chip. For details of procedures, see p. 630. 
Table 4. Hepatic genes down-regulated by the unsaponifiable fraction of olive oil

\begin{tabular}{|c|c|c|c|c|c|c|c|}
\hline Biological process & GenBank & Affymetrix ID & Name & Gene symbol & Olive oil & UE olive oil & Signal $\log _{2}$ ratio \\
\hline Carbohydrate metabolism & BC011139 & 1419146_a_at & Glucokinase & Gck & $63 \cdot 8$ & 7.9 & -3.2 \\
\hline Extracellular receptor & NM_007769 & 1418287_a_at & Endoglin & Dmbt1 & 319.6 & $52 \cdot 1$ & $-2 \cdot 2$ \\
\hline Glutathione conjugation & NM_008182 & 1421040_a_at & Glutathione $S$-transferase, $\alpha 2$ & Gsta2 & 269 & $59 \cdot 2$ & $-2 \cdot 3$ \\
\hline Glutathione conjugation & NM_010357 & 1416368_at & Glutathione $S$-transferase, $\alpha 4$ & Gsta4 & 219 & $47 \cdot 1$ & $-2 \cdot 1$ \\
\hline Glutathione conjugation & J03953 & 1427473_at & Glutathione $S$-transferase, mu 3 & Gstm3 & $217 \cdot 2$ & $45 \cdot 3$ & -1.9 \\
\hline Heat shock protein & M12573 & 1427126_at & Heat shock protein $1 \mathrm{~A}$ & Hspa1a & 634 & $220 \cdot 9$ & -1.5 \\
\hline Heat shock protein & U03561 & 1425964_x_at & Heat shock protein 1 & Hspb1 & $458 \cdot 1$ & $71 \cdot 3$ & $-2 \cdot 4$ \\
\hline Lipid metabolism & NM_025469 & 1415805_at & Colipase, pancreatic & Clps & $393 \cdot 1$ & $51 \cdot 3$ & $-2 \cdot 8$ \\
\hline Lipid metabolism & BC006872 & 1417257_at & Carboxyl ester lipase & $\mathrm{Cel}$ & $282 \cdot 7$ & 52 & -2.5 \\
\hline Lipid metabolism & Al326372 & 1433431_at & Pancreatic lipase & Pnlip & $858 \cdot 3$ & $78 \cdot 6$ & -3.3 \\
\hline Lipid metabolism & NM_018874 & 1415777_at & Pancreatic lipase related 1 & Pnliprp1 & 246.5 & $16 \cdot 6$ & $-2 \cdot 7$ \\
\hline Nuclease activity & NM_011271 & 1416523_at & Pancreatic ribonuclease $\mathrm{A} 1$ & Rnase1 & $305 \cdot 3$ & 73.4 & $-1 \cdot 6$ \\
\hline Proteolysis & AK003088 & 1428062_at & Carboxypeptidase A1 & Cpa1 & $800 \cdot 3$ & $70 \cdot 6$ & $-3 \cdot 3$ \\
\hline Proteolysis & AK003061 & 1428102_at & Carboxypeptidase B1 & Cpb1 & $536 \cdot 6$ & $84 \cdot 1$ & $-2 \cdot 6$ \\
\hline Proteolysis & NM_025583 & 1448220_at & Chymotrypsinogen & Chym & 778 & $59 \cdot 2$ & -3.3 \\
\hline Proteolysis & BC011218 & 1423693_at & Pancreatic elastase 1 & Ela1 & $690 \cdot 8$ & 231 & -1.9 \\
\hline Proteolysis & NM_007919 & 1448281_a_at & Elastase 2 & Ela2 & 666 & $79 \cdot 6$ & -3.3 \\
\hline Proteolysis & NM_026419 & 1415884_at & Pancreatic elastase 3B & Ela3b & 470.5 & $77 \cdot 6$ & -2 \\
\hline Proteolysis & BI348548 & 1433459_x_at & Trypsin 2 & Prss2 & $549 \cdot 3$ & $86 \cdot 1$ & $-2 \cdot 6$ \\
\hline Proteolysis & AB009661 & 1415954_at & Trypsin 4 & Try 4 & $436 \cdot 3$ & 29.4 & $-4 \cdot 1$ \\
\hline Surface protein & BC019567 & 1451228_a_at & Syncollin & Sycn & $242 \cdot 7$ & 14.5 & -3 \\
\hline Transcription factor & W13191 & 1426464_at & Nuclear receptor 1 D 1 & Nr1d1 & $262 \cdot 3$ & $59 \cdot 8$ & $-1 \cdot 8$ \\
\hline \multirow[t]{2}{*}{ Transcription factor } & BB550183 & 1438211_s_at & Albumin promoter binding protein & Dbp & 116.5 & $46 \cdot 1$ & -1.5 \\
\hline & BF581690 & 1428359_s_at & Expressed sequence tag & - & $203 \cdot 8$ & 19.5 & -2.5 \\
\hline
\end{tabular}

UE, unsaponifiable fraction-enriched.

${ }^{*}$ Data represent intensity of signal for each condition with the Affymetrix chip. For details of procedures, see p. 630. 
Table 5. Hepatic genes regulated by the unsaponifiable fraction of olive oil*

\begin{tabular}{|c|c|c|c|c|c|c|}
\hline & \multicolumn{2}{|c|}{ Olive oil ( $n 9)$} & \multicolumn{2}{|c|}{ UE olive oil ( $n$ 8) } & \multirow[b]{2}{*}{ Fold change } & \multirow[b]{2}{*}{ Signal $\log _{2}$ ratio } \\
\hline & Mean & SD & Mean & SD & & \\
\hline \multicolumn{7}{|c|}{ Genes up-regulated } \\
\hline Fabp5 & $1.0^{\mathrm{a}}$ & 0.8 & $5 \cdot 5^{\mathrm{b}}$ & 0.4 & $5 \cdot 3$ & $2 \cdot 4$ \\
\hline Lepr & $0.4^{\mathrm{a}}$ & 0.5 & $4 \cdot 1^{\mathrm{b}}$ & 0.2 & $10 \cdot 9$ & 3.4 \\
\hline Mt2 & $0.5^{\mathrm{a}}$ & 0.6 & $13 \cdot 6^{\mathrm{b}}$ & 1.5 & $29 \cdot 1$ & 4.8 \\
\hline Nnmt & $0.1^{a}$ & 0.3 & $2 \cdot 4^{\mathrm{b}}$ & 0.4 & $16 \cdot 8$ & $4 \cdot 1$ \\
\hline Orm2 & $2 \cdot 4^{\mathrm{a}}$ & 0.3 & $75 \cdot 2^{\mathrm{b}}$ & 2 & $31 \cdot 8$ & $5 \cdot 0$ \\
\hline Saa2 & $3 \cdot 4^{\mathrm{a}}$ & 0.3 & $108 \cdot 5^{\mathrm{b}}$ & 1 & $32 \cdot 2$ & $5 \cdot 0$ \\
\hline \multicolumn{7}{|c|}{ Genes down-regulated } \\
\hline Chym & $35 \cdot 1^{\mathrm{a}}$ & 0.1 & $5 \cdot 7^{\mathrm{b}}$ & 0.3 & 0.16 & $-2 \cdot 6$ \\
\hline Ela2 & $16 \cdot 2^{\mathrm{a}}$ & 0.1 & $4 \cdot 2^{b}$ & 0.3 & 0.26 & -1.9 \\
\hline Gck & $3.7^{\mathrm{a}}$ & 0.8 & $0.8^{\mathrm{b}}$ & 0.6 & 0.21 & $-2 \cdot 2$ \\
\hline Pnlip & $12 \cdot 2^{\mathrm{a}}$ & 3 & $2 \cdot 0^{\mathrm{b}}$ & 0.2 & 0.16 & -2.6 \\
\hline Try4 & $15 \cdot 2^{\mathrm{a}}$ & 0.1 & $4 \cdot 6^{\mathrm{b}}$ & 0.6 & 0.30 & -1.7 \\
\hline
\end{tabular}

UE, unsaponifiable fraction-enriched.

${ }^{\mathrm{a}, \mathrm{b}}$ Mean values within a row with unlike superscript letters were significantly different (Mann-Whitney $U$ test; $P<0 \cdot 001$ ).

* Data represent arbitrary units normalized to the $\beta$-actin expression for each condition with the quantitative real-time RT-PCR. For details of procedures, see p. 630.

significantly increased in their expressions by the presence of the unsaponifiable fraction of olive oil. The five down-regulated genes selected - Chym, Ela2, Gck, Pnlip, Try 4 - were significantly decreased in mice receiving the diet enriched in the unsaponifiable fraction of olive oil. Fig. 1 shows the correlation between the mean values of signal $\log _{2}$ ratio for the eleven genes with the microarray assay performed with pooled samples (Tables 3 and 4), and the mean of each group obtained after the analysis of samples from each animal in both experimental groups (Table 5). Good agreement between these procedures was obtained ( $r$ 0.9382, $P<0.0001)$ and all samples were correctly classified, although in two cases the magnitude of the response differed between both methods. Two genes showing mild expression change (signal $\log _{2}$ ratio $<1.5$ ), apolipoprotein 5 and paraoxonase 1, were also studied by Northern blotting, which confirmed their microassay results (data not shown). This indicates that pooled samples can be successfully used to provide an initial screening of gene expression in studies of this type, with the attending economic and time savings although with the limitation of no information on biological variability.

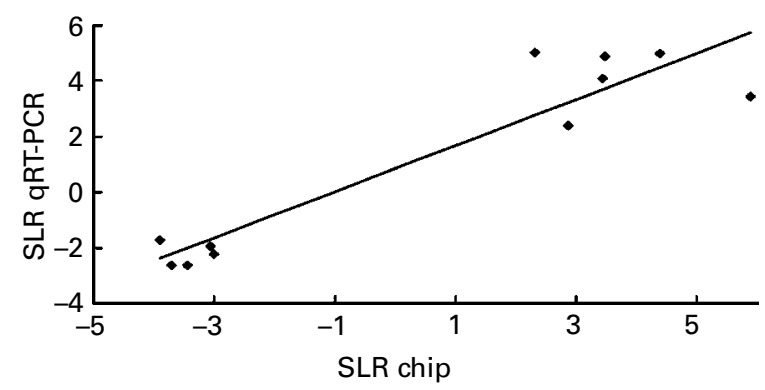

Fig. 1. Correlation analysis between microarray and quantitative real-time RT-PCR (qRT-PCR) data. The expression of eleven genes - Chym, Ela2, Fabp5, Gck, Lepr, Mt2, Nnmt, Orm2, Pnlip, Saa2 and Try4 - was individually studied by $\mathrm{qRT}-\mathrm{PCR}$ and normalized to the invariant $\beta$-actin gene. For details of procedures, see p. 630. The mean values obtained for signal $\log _{2}$ ratio (SLR) from individual analyses (see Table 5) were plotted against the microarray values which used pooled samples (see Tables 3 and 4). Good agreement between the procedures was seen $(r 0.9382, P<0.0001)$.

\section{Plasma presence of unsaponifiable-activated gene products}

Since five of the overexpressed genes (Orm1, Orm2, Orm3, Saal and Saa2) coded for circulating proteins that may influence general homeostasis, their plasma levels were determined. If the remarkable changes observed in the hepatic expression of these proteins were reflected in plasma to the same degree, this would make them highly attractive markers of the consumption of the unsaponifiable fraction of olive oil. Serum amyloid proteins are well-known modifiers of plasma lipoproteins but no physiological role for orosomucoid has been proposed besides its role in the acute phase response (Hochepied et al. 2003). Fig. 2(a) shows the results of Western analysis of serum amyloid protein concentration. The observed increase of Saa mRNA expression (Table 3) was not reflected in plasma in either the OO or UEOO mice, suggesting the absence of an acute phase reaction. To confirm this lack of acute phase response, the livers of animals consuming the different diets were examined histologically. Fig. 2(b) shows representative images of livers from animals of the two diet groups. For comparison, an image of an ApoE-deficient mouse of the same age that was fed the chow diet with no added oil of any type is included (marked as control group). The liver of this control animal shows marked steatosis, in agreement with the described accumulation of lipids in this model (Sehayek et al. 2000). Interestingly, both experimental diets alleviated these steatotic features. No inflammatory cells were detected in the liver of any animal, suggesting that the UEOO diet does not induce an acute phase response. However, the increased hepatic Orm 2 mRNA levels observed in the chip analysis were confirmed by qRT-PCR (Fig. 3(A)) and were reflected in the plasma concentration of animals consuming the UEOO diet (Fig. 3(C)). The present results indicate that the increase in hepatic Orm 2 mRNA leads to increased concentrations of the protein product in plasma.

To determine whether this induction of $\mathrm{Orm} 2$ also occurred in apoE-deficient mice with the C57BL/6J genetic background, their livers were studied for the expression of this gene. Although the UEOO diets led to a reduction in hepatic 
a
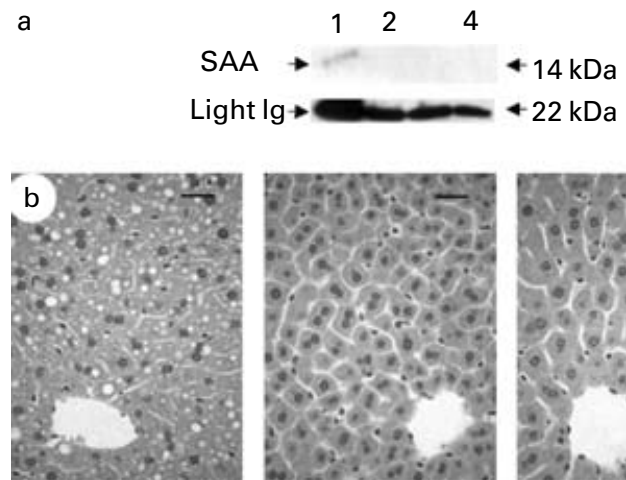

Chow

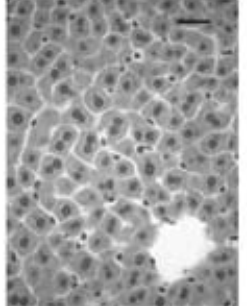

OO diet

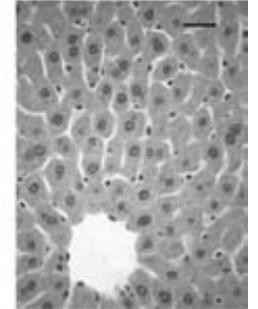

UEOO diet
Fig. 2. Absence of acute phase reaction in mice fed the different diets (OO diet, diet supplemented with olive oil; UEOO diet, diet supplemented with unsaponifiable fraction-enriched olive oil). (a), Plasma serum amyloid A (SAA) Western blot analysis. Lane 1, a positive control corresponding to rat plasma from an animal treated with turpentine to induce the acute phase reaction. Lanes $2-4$, plasma from mice consuming the different diets: chow, OO diet and UEOO diet, respectively. Light chain Ig detection was used as a loading control. (b), Representative liver micrographs from apoE-deficient mice consuming the different diets (bars $=25 \mu \mathrm{m}$ ). For details of procedures, see p. 630.

Orm2 mRNA levels (Fig. 3(B)), surprisingly this was not reflected at the plasma level (data not shown). The increase in hepatic Orm2 mRNA expression is probably a specific response elicited by the unsaponifiable fraction of olive oil,

A

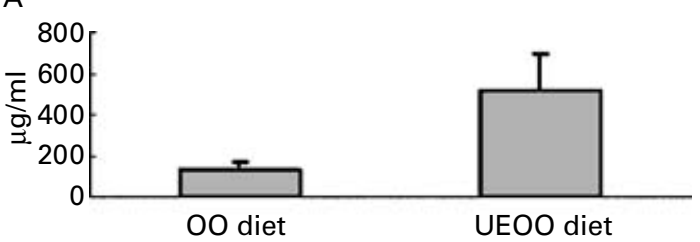

B

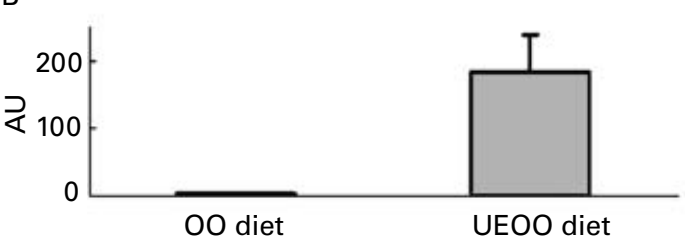

C

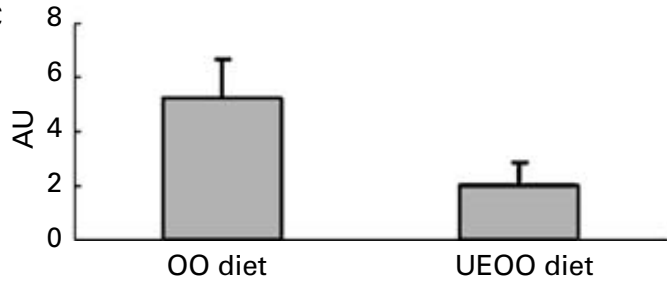

Fig. 3. Influence of genetic background on orosomucoid expression in apoEdeficient mice consuming the different diets (OO diet, diet supplemented with olive oil; UEOO diet, diet supplemented with unsaponifiable fraction-enriched olive oil). (A), Plasma orosomucoid 2 levels in apoE-deficient mice with C57BL/6J $\times$ Ola129 genetic background. $(B, C)$, mRNA expression for orosomucoid 2 in livers of apoE-deficient mice with C57BL/6J $\times$ Ola129 (B) and C57BL/6J (C) genetic backgrounds (determined by quantitative real-time RT-PCR). For details of procedures, see p. 630. Values are means with their standard errors depicted by vertical bars. Mean values were significantly different from those of the $\mathrm{OO}$ diet (Mann-Whitney $U$ test): ${ }^{*} P<0.001$. and is not related to an acute phase response but conditioned by the genetic background of the mice.

\section{Effects of mouse genetic background on the response to unsaponifiable fraction-enriched olive oil}

To investigate which of the selected genes - Chym, Ela2, Fabp5, Gck, Lepr, Mt2, Nnmt, Pnlip, Saa2, Try4 - were influenced by the genetic background, their expressions in apoEdeficient mice (C57BL/6J genetic background) receiving both diets were assayed by qRT-PCR (normalized to the invariant gene $\beta$-actin). The results are expressed as signal $\log _{2}$ ratios in both genetic backgrounds (Fig. 4). Interestingly, no Pnlip expression was detected in the livers of mice with the C57BL/6J background and lesser variability of response was observed in these mice. For the genes Lepr and Saa2, a significant opposite response was seen in mice of different genetic background. In contrast, for seven other genes the influence of the UEOO diet was similar in both types of mice $(M t 2$, Chym and Ela2 expressions), although the magnitude of response significantly differed (more pronounced for the Fabp5 gene in the C57BL/6J background, and less so in genes Gck, Nnmt and Try4 in the C57BL/6J $\times$ Ola129 background). The present results further illustrate that genetic background may influence the response to the unsaponifiable fraction of olive oil.

\section{Discussion}

The unsaponifiable fraction of olive oil remarkably influenced the activity of several genes. The nutrigenomic approach of the present work clearly shows the important effect of this fraction. Some of its components, such as phytosterols (Plosch et al. 2004) and vitamin E (Barella et al. 2004), have been shown to affect the expression of certain genes.

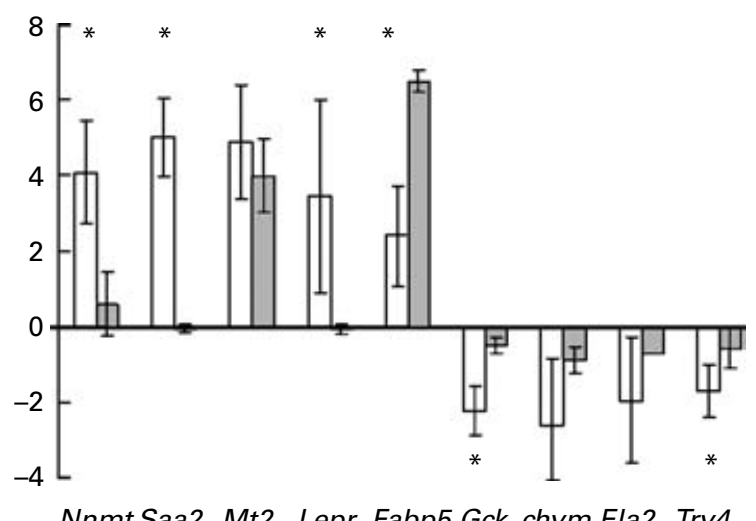

Fig. 4. Influence of genetic background of apoE-deficient mice on the pattern of gene expression in response to the diet supplemented with unsaponifiable fraction-enriched olive oil (UEOO diet). Data are expressed as signal $\log _{2}$ ratios of hepatic mRNA expression (as determined by quantitative real-time RT-PCR) for each gene in apoE-deficient mice with C57BL/6J $\times$ Ola129 ( $\square$ ) and C57BL/6J $(\square)$ genetic backgrounds consuming either the diet supplemented with olive oil (OO diet) or the UEOO diet. Animals receiving the OO diet were used as the reference against which to compare the effects of the UEOO diet. For details of procedures, see p. 630. Values are means with their standard deviations depicted by vertical bars. ${ }^{*} P<0.001$ between genetic backgrounds according to the Mann-Whitney $U$ test. 
Others, such as maslinic acid (Montilla et al. 2003; MárquezMartín et al. 2006) and erythrodiol (Rodriguez-Rodriguez et al. 2004), are biologically active compounds but it is not known whether they influence the expression of any gene. Independent of the mechanism involved, the present results reveal the additional effects of the unsaponifiable fraction with respect to the influence of olive oil, and support the idea that not all MUFA-containing oils behave in the same way (Kritchevsky et al. 1984; Kris-Etherton et al. 1999).

The huge amounts of information provided by microarrays requires further action be undertaken if meaningful and manageable data are to be obtained, such as selecting only the genes with the highest expression changes (Dutta et al. 2003; Vergnes et al. 2003; Artieda et al. 2005; Calpe-Berdiel et al. 2005) or those involved in a certain metabolic pathway (Horton et al. 2003; Kreeft et al. 2005). In the present work, analysis was performed by subjecting the microarray data to two rounds of selection. First, a restrictive step was performed, selecting only those genes with a signal $\log _{2}$ ratio of $\pm 1 \cdot 5$. With this criterion, only thirty genes were found to be remarkably up-regulated and twenty-four notably down-regulated. Second, only those genes whose expression was strongly modified were deemed to be potential markers of the intake of the unsaponifiable fraction. The strong modification of the expression of these genes was individually confirmed by qRT-PCR. Good agreement was observed between the Affymetrix chip and qRT-PCR data (Fig. 1). In high-density microarrays, such as the Affymetrix MOE430A gene chip, several probes are used for the same gene, therefore the main concern regarding repeatability is the natural individual variability of mRNA expression. Minimum information about a Microarray experiment (MIAME) standards recommend using several chips for this reason (http://www. mged.org/index.html), but this is not the only option and sometimes it may be too stringent in terms of sample demands, time, cost and the manageability of information. The present data clearly show that pooling RNA from different animals and using this in microarray analysis is a reliable screening method for the search of biological effects in terms of saving samples, time and economic resources, as other authors have found (Napoli et al. 2002; Dutta et al. 2003; Artieda et al. 2005; Calpe-Berdiel et al. 2005; Kreeft et al. 2005). However, the main drawback of this approach is the lack of information on biological variability of individual samples. This limitation, also observed in other areas (Peng et al. 2003), may be particularly important in the nutrition field in order to distinguish dietary responders and non-responders. Therefore, the experimenter should be aware of this caveat before deciding to pool samples.

The eleven genes whose expression was strongly modified - Chym, Ela2, Fabp5, Gck, Lepr, Mt2, Nnmt, Orm2, Pnlip, Saa2, Try4 - were tested for their suitability as markers of the consumption of the unsaponifiable fraction. Their dependency on genetic background in apoE-deficient mice was also analysed. Seven of these genes - Chym, Ela2, Fabp5, Gck, Mt2, Nnmt and Try4 - were representative markers of the presence of the unsaponifiable fraction of olive oil in the diet, independent of the genetic background. Three of these genes - Chym, Ela 2 and Try 4 - are involved in proteolysis and showed reduced expression in the UEOO animals. Gck, an enzyme involved in glucose metabolism and also repressed in animals receiving high-fat diets, showed similar behaviour (Dutta et al. 2003). The opposite (up-regulation) was observed for the expressions of Fabp5, Mt2 and Nnmt. Fabp5 (mall) is considered to be an epidermal protein although it is also expressed in adipocytes (Maeda et al. 2003) and the liver (see GenBank accession AK167389 for a clone isolated from a liver cDNA library, and the present data). The exact role of this protein is not yet completely known, although it has been proposed to bind leukotriene A4 (Zimmer et al. 2004) and to play a role in systemic insulin sensitivity (Maeda et al. 2003). The change in its expression induced by the UEOO diet was particularly dramatic in the C57BL/ $6 \mathrm{~J}$ animals. Mt2 is thought to be associated with obesity since knock-out mice lacking this gene develop this problem (Miura \& Koizumi, 2005). In both studied substrates, the expression of this gene was up-regulated (Fig. 4). Nnmt has been recently associated with plasma homocysteine levels (Souto et al. 2005). Its genetic background-dependent response might explain the variation in homocysteine levels in different strains of mice. Taken as a whole, the present results suggest that the unsaponifiable components of olive oil play an important role in controlling the expression of genes with roles in obesity, insulin sensitivity and cardiovascular risk factors, and that it deserves further attention.

The expression levels of Lepr, Orm2 and Saa2 act as markers of the presence of the unsaponifiable fraction of olive oil in the diet, but in a genetic background-dependent fashion. No increase in plasma serum amyloid A was seen, but circulating levels of orosomucoid appeared to be elevated in mice with the hybrid genetic background (C57BL/6J $\times$ OLA129). The induction of orosomucoids has to date been attributed to acute phase reactions (Hochepied et al. 2003). In this regard, the absence of any hepatic steatosis or inflammation plus a lack of change in serum amyloid A after the administration of the unsaponifiable fraction suggests that increased orosomucoid plasma levels are a unique response elicited by these compounds via the induction of Orm2 expression. Recent studies have found that subjects with increased plasma concentrations of orosomucoid have higher levels of vitamin A (Thurnham et al. 2003). In addition, in transgenic mice overexpressing srebpl and srebp2, transcriptional factors involved in lipid metabolism, increased expression of this gene has also been described (Horton et al. 2003) although at a lower intensity than in mice consuming the UEOO diet. Together, the data suggest an unknown role for orosomucoid that might vary depending on the genetic background.

The absence of hepatic steatosis and inflammation after the administration of either diet is an interesting finding that confirms previous data showing hepatic TAG (in other experimental models) to be reduced when olive oil is consumed (Deng et al. 2004). This effect is lost, however, when a higher percentage olive oil intake is provided or when the intake is accompanied by cholesterol (Acín et al. 2005). Overall, the results indicate that in dyslipidaemic apoE-deficient mice, olive oil provides protection against hepatic steatosis until a certain fat intake is reached. This would be especially true in low-cholesterol diets such as with the traditional Mediterranean diet.

In conclusion, this nutrigenomic approach clearly illustrates the important effects of the unsaponifiable fraction of olive oil. The present results suggest that it is no longer appropriate to 
speak of MUFA-enriched oils (avocado, oleic acid-enriched safflower, oleic acid-enriched sunflower, olive and peanut oils) as though all had the same effects. Future studies should be aware of this to avoid confusion - both to researchers and consumers. The present approach also shows new connections between nutrition and gene expression. A gene product with unknown biological function, orosomucoid, was up-regulated to an extent depending on the genetic background of the mice. Fabp5 and $M t 2$ were strongly up-regulated while the expression of several proteases was repressed by the UEOO diet. These modifications in expression could be used as markers of the intake of the unsaponifiable fraction of olive oil. The present results also show the usefulness of Affymetrix chip technology for characterizing gene expression levels in response to nutritional components in intact animal systems.

\section{Acknowledgements}

V. R.-G. and J. O. contributed equally to this work. This research was supported by grants FEGA-FEOGA (CAO99014), Ministerio de Educación y Ciencia, CICYT (SAF200408 173-C03-02 and AGL2005-00572), Junta de Andalucía (CAO01-002), FISS 01/0202, Redes FISS de investigación cooperativa C03-01 and G03-140 and by the Fundación Española del Corazón. R. C., S. A., M. A. N. and N. G. were recipients of DGA, FEGA-FEOGA and Fundación CuencaVilloro fellowships. We thank Drs C. Junquera and L. Osaba of Progenika Biopharma for performing the microarray analyses, and Dr Martínez for critical reading of the manuscript. Thanks are also due to Angel Beltrán, Jesús Cazo, Jesús Navarro, Carmen Navarro and Clara Tapia of the Unidad Mixta de Investigación for their invaluable help in maintaining the experimental animals. We also thank Adrian Burton for editorial assistance.

\section{References}

Abia R, Pacheco YM, Perona JS, Montero E, Muriana FJ \& RuizGutierrez V (2001) The metabolic availability of dietary triacylglycerols from two high oleic oils during the postprandial period does not depend on the amount of oleic acid ingested by healthy men. $J$ Nutr 131, 59-65.

Acín S, Navarro MA, Carnicer R, Arbonés JM, Guzmán MA, Arnal C, Beltrán G, Uceda M, Maeda N \& Osada J (2005) Dietary cholesterol suppresses the ability of olive oil to delay the development of atherosclerotic lesions in apolipoprotein E knockout mice. Atherosclerosis 182, 17-28.

Arbonés-Mainar JM, Navarro MA, Acín S, Guzmán MA, Arnal C, Surra JC, Carnicer R, Roche HM \& Osada J (2006a) trans-10, cis-12- and cis-9, trans-11-Conjugated linoleic acid isomers selectively modify HDL-apolipoprotein composition in apolipoprotein $\mathrm{E}$ knockout mice. J Nutr 136, 353-359.

Arbonés-Mainar JM, Navarro MA, Guzmán MA, Arnal C, Surra JC, Acín S, Carnicer R, Osada J \& Roche HM (2006b) Selective effect of conjugated linoleic acid isomers on atherosclerotic lesion development in apolipoprotein E knockout mice. Atherosclerosis, 189, $318-327$.

Artieda M, Cenarro A, Junquera C, Lasierra P, Martinez-Lorenzo MJ, Pocovi M \& Civeira F (2005) Tendon xanthomas in familial hypercholesterolemia are associated with a differential inflammatory response of macrophages to oxidized LDL. FEBS Lett 579, 4503-4512.

Barella L, Muller PY, Schlachter M, Hunziker W, Stocklin E, Spitzer V, Meier N, de Pascual-Teresa S, Minihane AM \& Rimbach G (2004) Identification of hepatic molecular mechanisms of action of alpha-tocopherol using global gene expression profile analysis in rats. Biochim Biophys Acta 1689, 66-74.

Calleja L, Paris MA, Paul A, Vilella E, Joven J, Jimenez A, Beltran G, Uceda M, Maeda N \& Osada J (1999) Low-cholesterol and high-fat diets reduce atherosclerotic lesion development in ApoEknockout mice. Arterioscler Thromb Vasc Biol 19, 2368-2375.

Calpe-Berdiel L, Escola-Gil JC, Ribas V, Navarro-Sastre A, GarcesGarces J \& Blanco-Vaca F (2005) Changes in intestinal and liver global gene expression in response to a phytosterol-enriched diet. Atherosclerosis 181, 75-85.

de la Puerta R, Martinez Dominguez ME, Ruiz-Gutierrez V, Flavill JA \& Hoult JR (2001) Effects of virgin olive oil phenolics on scavenging of reactive nitrogen species and upon nitrergic neurotransmission. Life Sci 69, 1213-1222.

de la Puerta-Vazquez R, Martinez-Dominguez E, Sanchez Perona J \& Ruiz-Gutierrez V (2004) Effects of different dietary oils on inflammatory mediator generation and fatty acid composition in rat neutrophils. Metabolism 53, 59-65.

den Boer M, Voshol PJ, Kuipers F, Havekes LM \& Romijn JA (2004) Hepatic steatosis: a mediator of the metabolic syndrome. Lessons from animal models. Arterioscler Thromb Vasc Biol 24, 644-649.

Deng X, Elam MB, Wilcox HG, Cagen LM, Park EA, Raghow R, Patel D, Kumar P, Sheybani A \& Russell JC (2004) Dietary olive oil and menhaden oil mitigate induction of lipogenesis in hyperinsulinemic corpulent JCR:LA-cp rats: microarray analysis of lipid-related gene expression. Endocrinology 145, 5847-5861.

Dutta R, Singh U, Li TB, Fornage M \& Teng BB (2003) Hepatic gene expression profiling reveals perturbed calcium signaling in a mouse model lacking both LDL receptor and Apobec1 genes. Atherosclerosis 169, 51-62.

Folch J, Less M \& Sloan-Stanley GH (1957) A simple method for the isolation and purification of total lipids from the animal tissues. $J$ Biol Chem 33, 497-509.

Gilsbach R, Kouta M, Bönisch H \& Brüss M (2006) Comparison of in vitro and in vivo reference genes for internal stardardization of real-time PCR data. BioTechniques 40, 173-177.

Herrera MD, Perez-Guerrero C, Marhuenda E \& Ruiz-Gutierrez V (2001) Effects of dietary oleic-rich oils (virgin olive and higholeic-acid sunflower) on vascular reactivity in Wistar-Kyoto and spontaneously hypertensive rats. Br J Nutr 86, 349-357.

Hochepied T, Berger FG, Baumann H \& Libert C (2003) Alpha(1)acid glycoprotein: an acute phase protein with inflammatory and immunomodulating properties. Cytokine Growth Factor Rev 14, $25-34$.

Horton JD, Shah NA, Warrington JA, Anderson NN, Park SW, Brown MS \& Goldstein JL (2003) Combined analysis of oligonucleotide microarray data from transgenic and knockout mice identifies direct SREBP target genes. Proc Natl Acad Sci U S A 100, $12027-12032$.

Keys A (1995) Mediterranean diet and public health: personal reflections. Am J Clin Nutr 61, Suppl., 1321S-1323S.

Keys A, Menotti A \& Karvonen MJ (1986) The diet and 15-year death rate in the Seven Countries Study. Am J Epidemiol 124, 903-915.

Kreeft AJ, Moen CJ, Porter G, Kasanmoentalib S, Sverdlov R, van Gorp PJ, Havekes LM, Frants RR \& Hofker MH (2005) Genomic analysis of the response of mouse models to high-fat feeding shows a major role of nuclear receptors in the simultaneous regulation of lipid and inflammatory genes. Atherosclerosis 182, 249-257.

Kris-Etherton PM, Pearson TA, Wan Y, Hargrove RL, Moriarty K, Fishell V \& Etherton TD (1999) High-monounsaturated fatty 
acid diets lower both plasma cholesterol and triacylglycerol concentrations. Am J Clin Nutr 70, 1009-1015.

Kritchevsky D, Tepper SA, Klurfeld DM, Vesselinovitch D \& Wissler RW (1984) Experimental atherosclerosis in rabbits fed cholesterol-free diets. Part 12. Comparison of peanut and olive oils. Atherosclerosis 50, 253-259.

Krzywkowski P, Ghribi O, Gagne J, Chabot C, Kar S, Rochford J, Massicotte G \& Poirier J (1999) Cholinergic systems and longterm potentiation in memory-impaired apolipoprotein E-deficient mice. Neuroscience 92, 1273-1286.

Maeda K, Uysal KT, Makowski L, Gorgun CZ, Atsumi G, Parker RA, Bruning J, Hertzel AV, Bernlohr DA \& Hotamisligil GS (2003) Role of the fatty acid binding protein mall in obesity and insulin resistance. Diabetes 52, 300-307.

Márquez-Martín A, de la Puerta-Vázquez R, Fernández-Arche A \& Ruiz-Gutiérrez V (2006) Suppressive effect of maslinic acid from pomace olive oil on oxidative stress and cytokine production in stimulated murine macrophages. Free Radic Res, 40, 295-302.

Masliah E, Mallory M, Ge N, Alford M, Veinbergs I \& Roses AD (1995) Neurodegeneration in the central nervous system of apoEdeficient mice. Exp Neurol 136, 107-122.

Mata P, Alvarez-Sala L, Rubio M, Nuño J \& De Oya M (1992) Effects of long-term monounsaturated- vs polyunsaturatedenriched diets on lipoproteins in healthy men and women. Am J Clin Nutr 55, 846-850.

Mattson F \& Grundy S (1985) Comparison of the effects of dietary saturated, monounsaturated and polyunsaturated fatty acids on plasma lipids and lipoprotein in man. J Lipid Res 26, 194-202.

Mensink RP \& Katan MB (1989) Effect of a diet enriched with monounsaturated or polyunsaturated fatty acids on levels of low-density and high-density lipoprotein cholesterol in healthy women and men. $N$ Engl J Med 321, 436-441.

Miura N \& Koizumi S (2005) Gene expression profiles in the liver and kidney of metallothionein-null mice. Biochem Biophys Res Commun 332, 949-955.

Montilla MP, Agil A, Navarro MC, Jimenez MI, Garcia-Granados A, Parra A \& Cabo MM (2003) Antioxidant activity of maslinic acid, a triterpene derivative obtained from Olea europaea. Planta Med 69, $472-474$.

Napoli C, de Nigris F, Welch JS, Calara FB, Stuart RO, Glass CK \& Palinski W (2002) Maternal hypercholesterolemia during pregnancy promotes early atherogenesis in LDL receptor-deficient mice and alters aortic gene expression determined by microarray. Circulation 105, 1360-1367.

Oitzl MS, Mulder M, Lucassen PJ, Havekes LM, Grootendorst J \& de Kloet ER (1997) Severe learning deficits in apolipoprotein Eknockout mice in a water maze task. Brain Res 752, 189-196.

Osada J, Joven J \& Maeda N (2000) The value of apolipoprotein E knockout mice for studying the effects of dietary fat and cholesterol on atherogenesis. Curr Opin Lipidol 11, 25-29.

Peng X, Wood CL, Blalock EM, Chen KC, Landfield PW \& Stromberg AJ (2003) Statistical implications of pooling RNA samples for microarray experiments. BMC Bioinformatics 4, 1-9.

Pérez-Camino MC \& Cert A (1999) Quantitative determination of hydroxy pentacyclic triterpene acids in vegetable oils. J Agric Food Chem 47, 1558-1562.
Perona JS, Cabello-Moruno R \& Ruiz-Gutiérrez V (2006) The role of virgin olive oil components in the modulation of endothelial function. J Nutr Biochem, 17, 429-445.

Perona JS, Canizares J, Montero E, Sanchez-Dominguez JM \& RuizGutierrez V (2003) Plasma lipid modifications in elderly people after administration of two virgin olive oils of the same variety (Olea europaea var. hojiblanca) with different triacylglycerol composition. Br J Nutr 89, 819-826.

Perona JS \& Ruiz-Gutierrez V (2004) Quantification of major lipid classes in human triacylglycerol-rich lipoproteins by high performance liquid chromatography with evaporative light-scattering detection. J Sep Sci 27, 653-659.

Plosch T, Bloks VW, Terasawa Y, et al. (2004) Sitosterolemia in ABC-transporter G5-deficient mice is aggravated on activation of the liver-X receptor. Gastroenterology 126, 290-300.

Rodriguez-Rodriguez R, Herrera MD, Perona JS \& Ruiz-Gutierrez V (2004) Potential vasorelaxant effects of oleanolic acid and erythrodiol, two triterpenoids contained in 'orujo' olive oil, on rat aorta. Br J Nutr 92, 635-642.

Ruiz-Gutierrez V, Muriana FJ, Guerrero A, Cert AM \& Villar J (1996) Plasma lipids, erythrocyte membrane lipids and blood pressure of hypertensive women after ingestion of dietary oleic acid from two different sources. J Hypertens 14, 1483-1490.

Sanchez Perona J, Martínez-González J, Sánchez-Domínguez JM, Badimon L \& Ruiz-Gutierrez V (2004) The unsaponifiable fraction of virgin olive oil in chylomicrons from men improves the balance between vasoprotective and pro-thrombotic factors released by endothelial cells. J Nutr 134, 3284-3289.

Sehayek E, Shefer S, Nguyen LB, Ono JG, Merkel M \& Breslow JL (2000) Apolipoprotein E regulates dietary cholesterol absorption and biliary cholesterol excretion: studies in C57BL/6 apolipoprotein E knockout mice. Proc Natl Acad Sci U S A 97, 3433-3437.

Souto JC, Blanco-Vaca F, Soria JM, Buil A, Almasy L, OrdonezLlanos J, Martin-Campos JM, Lathrop M, Stone W, Blangero J \& Fontcuberta J (2005) A genomewide exploration suggests a new candidate gene at chromosome $11 \mathrm{q} 23$ as the major determinant of plasma homocysteine levels: results from the GAIT project. Am J Hum Genet 76, 925-933.

Thurnham DI, McCabe GP, Northrop-Clewes CA \& Nestel P (2003) Effects of subclinical infection on plasma retinol concentrations and assessment of prevalence of vitamin A deficiency: meta-analysis. Lancet 362, 2052-2058.

Vergnes L, Phan J, Strauss M, Tafuri S \& Reue K (2003) Cholesterol and cholate components of an atherogenic diet induce distinct stages of hepatic inflammatory gene expression. J Biol Chem 278, 42774-42784.

Visioli F, Galli C, Grande S, Colonnelli K, Patelli C, Galli G \& Caruso D (2003) Hydroxytyrosol excretion differs between rats and humans and depends on the vehicle of administration. $J$ Nutr 133, 2612-2615.

Visioli F, Galli C, Plasmati E, Viappiani S, Hernandez A, Colombo C \& Sala A (2000) Olive phenol hydroxytyrosol prevents passive smoking-induced oxidative stress. Circulation 102, 2169-2171.

Zimmer JS, Dyckes DF, Bernlohr DA \& Murphy RC (2004) Fatty acid binding proteins stabilize leukotriene A4: competition with arachidonic acid but not other lipoxygenase products. J Lipid Res 45, 2138-2144. 